\title{
BMJ
}

\section{Reflux related hospital admissions after fundoplication in children with neurological impairment: retrospective cohort study}

\begin{abstract}
Rajendu Srivastava, associate professor, ${ }^{1}$ attending physician, ${ }^{2}$ Jay G Berry, instructor, ${ }^{3,4}$ Matt Hall, senior statistician, ${ }^{5}$ Earl C Downey, professor, ${ }^{6}$ attending physician, ${ }^{2}$ Molly O'Gorman, associate professor, ${ }^{7}$ attending physician, ${ }^{2}$ I Michael Dean, professor and vice chairman, attending physician, ${ }^{8,2}$ Douglas C Barnhart, associate professor, ${ }^{6}$ attending physician ${ }^{2}$
\end{abstract}

\section{ABSTRACT}

Division of Inpatient Medicine, Department of Pediatrics, University of Utah Health Sciences Center, Salt Lake City, UT, USA

2Primary Children's Medical

Center, Intermountain Healthcare, Salt Lake City

${ }^{3}$ Complex Care Service, Children's Hospital, Boston, MA, USA

${ }^{4}$ Harvard Medical School, Boston, MA, USA

${ }^{5}$ Child Health Corporation of America, Shawnee Mission, KS, USA

${ }^{6}$ Division of Pediatric Surgery, Department of Surgery, University of Utah Health Sciences Center

${ }^{7}$ Division of Pediatric Gastroenterology, Department of Pediatrics, University of Utah Health Sciences Center

${ }^{8}$ Division of Pediatric Critical Care, Department of Pediatrics,

University of Utah Health Sciences Center

Correspondence to: $\mathrm{R}$ Srivastava raj.srivastava@hsc.utah.edu

Cite this as: BMJ 2009;339:b4411 doi:10.1136/bmj.b4411 related hospital admissions, defined as the post-
Objective To examine the impact of fundoplication on reflux related hospital admissions for children with neurological impairment.

Design Retrospective, observational cohort study. Setting 42 children's hospitals in the United States. Participants 3721 children with neurological impairment born between 2000 and 2005 who had at least one hospital admission at a study hospital before their fundoplication.

Intervention Fundoplication.

Main outcome measures Incident rate ratio for reflux fundoplication admission rate divided by the prefundoplication admission rate.

Results Of the 955285 children born during the study period, 144749 (15\%) had neurological impairment. Of these, 27720 (19\%) were diagnosed as having gastrooesophageal reflux disease, of whom 6716 (24\%) had a fundoplication. Of these, 3721 (55\%) had at least one previous hospital admission and were included in the study cohort. After fundoplication, hospital admissions decreased for any reflux related cause (incident rate ratio $0.69,95 \%$ confidence interval 0.67 to $0.72 ; P<0.01$ ), aspiration pneumonia $(0.71,0.62$ to $0.81 ; \mathrm{P}<0.01)$, gastro-oesophageal reflux disease $(0.60,0.57$ to 0.63 ; P<0.01), and mechanical ventilation $(0.40,0.37$ to 0.43 ; $\mathrm{P}<0.01)$, after adjustment for other patient and hospital related factors that may influence reflux related hospital admissions. Hospital admissions increased for asthma (incident rate ratio $1.52,1.38$ to $1.67 ; \mathrm{P}<0.01$ ) and remained constant for pneumonia (1.07, 0.98 to 1.17; $\mathrm{P}=0.16$ )

Conclusions Children with neurological impairment who have fundoplication had reduced short term reflux related hospital admissions for aspiration pneumonia, gastrooesophageal reflux disease, and mechanical ventilation. However, admissions for pneumonia remained constant and those for asthma increased after fundoplication. Comparative effectiveness data for other treatments (such as gastrojejunal feeding tubes) are unknown.

\section{INTRODUCTION}

Aspiration pneumonia is the most common cause of death in children with severe neurological impairment. ${ }^{1-4}$ These children have dysfunctional swallowing and gastro-oesophageal reflux disease, which places them at risk of aspiration pneumonia. ${ }^{5-7}$ The most common surgical treatment for medically refractory gastro-oesophageal reflux disease is the anti-reflux procedure known as fundoplication. The surgery involves wrapping part of the stomach around the lower oesophagus, and this compression of the oesophagus prevents the stomach contents from being able to reflux. Fundoplication is the third most common procedure done by paediatric surgeons. ${ }^{8}$ Approximately $40 \%$ of paediatric fundoplications in the United States are done in children with neurological impairment. ${ }^{9}$

The literature provides some estimates of the effects of fundoplication in children with neurological impairment. Complications are reported in $4 \%$ to $39 \%$ of children, and mortality is between $1 \%$ and $3 \%{ }^{6810-13}$ Previous studies have reported contradictory results of the effectiveness of fundoplication as regards symptoms of gastro-oesophageal reflux disease. Outcomes reported by physicians show abatement of symptoms in $85 \%$ of children. ${ }^{8}$ Other studies report recurrence of symptoms of gastro-oesophageal reflux disease after fundoplication in up to $56 \%$ of children and recurrence of aspiration pneumonia in up to $39 \% .^{111415}$ These retrospective operative case series report outcomes that are subject to bias, and they are limited by variability in loss of patients to follow-up. In addition, they do not describe explicit selection criteria or specific indications for the procedure. The lack of high quality evidence for this common clinical scenario hinders both clinicians and caregivers in deciding whether surgery would benefit a child.

Multicentre prospective trials evaluating the impact of comparative therapeutic interventions for gastrooesophageal reflux disease in children with neurological impairment are being called for, in order to 
overcome the methodological flaws of previous retrospective studies. ${ }^{16-20}$ However, the ideal primary outcome is unclear. Potential outcomes that evaluate the impact of anti-reflux interventions include resolution of symptoms, nutritional outcomes, children's and caregivers' health related quality of life, complications, cost, morbidity, and mortality. ${ }^{192122}$

Reflux related hospital admission is an objective and more precise outcome of fundoplication for gastro-oesophageal reflux disease. ${ }^{18}$ Given that these admissions reflect severe and costly complications of gastro-oesophageal reflux disease, their assessment provides a composite assessment of the importance of the condition in this population, incorporating many of the morbidities. Reflux related hospital admission has the benefit of being subject to less bias than some other outcomes, such as resolution of symptoms; it also affects health related quality of life by reducing the time spent in the hospital for children and their caregivers.

A study in a single US state by Goldin et al examined lifetime risk after fundoplication and showed some reduction in reflux related admissions. ${ }^{18} \mathrm{We}$ were able to extend the methods of this study to examine the impact of fundoplication on reflux related hospital admissions for children with neurological impairment within 42 freestanding children's hospitals across 35 US states. The results of our study provide an estimate of the impact of first fundoplication on severe sequelae of gastro-oesophageal reflux disease in children with neurological impairment and inform the development of a future multicentre clinical trial.

\section{METHODS}

\section{Patients}

Data for this retrospective observational cohort study came from the Pediatric Health Information System administrative database, developed by the Child Health Corporation of America (Shawnee Mission, KS), a business alliance of children's hospitals. The database contains inpatient demographic, diagnostic, and procedural data from 42 not for profit, freestanding paediatric hospitals in the United States. Thomson Reuters (Evanston, IL) manages the data warehouse function for the database. Data are subjected to several checks of reliability and validity and processed into data quality reports. Patients are tracked for repeat hospital admissions at the same children's hospital by use of a unique identifier.

\section{Study population}

We used the following inclusion criteria to create the cohort: birth date during the study enrolment period (2000-5), at least one admission to any of the 42 Pediatric Health Information System hospitals, and an ICD-9-CM (international classification of diseases, 9th revision, clinical modification) diagnostic code for neurological impairment. We then followed this cohort and included patients who had a diagnosis code for gastro-oesophageal reflux disease (530.11, 5301.81) and a procedure code for fundoplication $(44.66,44.67)$. We created the cohort in this manner

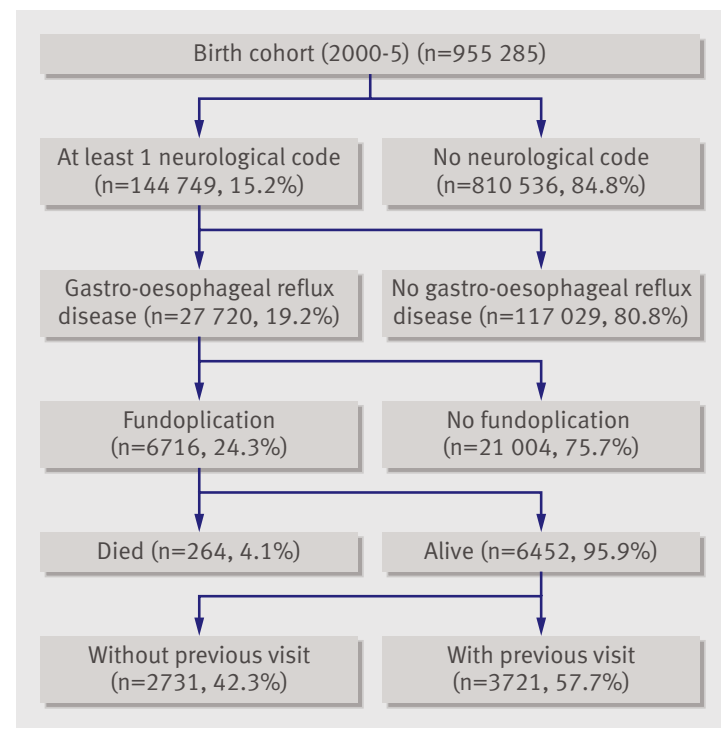

Fig 1| Study cohort.

to ensure that we would capture the first fundoplication. We followed the cohort for one year after the first fundoplication to capture reflux related hospital admissions. We used the same codes for reflux related admissions on the cohort before fundoplication. We excluded children with neurological impairment and gastro-oesophageal reflux disease who did not have at least one hospital admission before the fundoplication for two reasons: their care was not solely based at the Pediatric Health Information System hospital, and they may constitute a different patient population; and our methods did not allow for a zero pre-fundoplication admission rate. For subanalyses, we divided the study cohort into two groups: children with previous hospital admissions that were not related to reflux and those with at least one previous reflux related admissions.

\section{Patients' characteristics}

Demographics -Demographic characteristics included sex, ethnicity (non-Hispanic white, black, Hispanic, Asian, and other), payer (government, private, other), discharge disposition (home, died, other), and age ( $<3$ months, 3 to $<6$ months, 6 to $<12$ months, 12 to $<18$ months, 18 to $<36$ months, $\geq 36$ months) on the basis of observation of the distribution of cases for this young cohort $\left(<7\right.$ years) and published data. ${ }^{18}$

Neurological impairment-We defined neurological impairment as static or progressive, central and/or peripheral neurological diagnoses associated with chronic functional and/or intellectual impairment. We determined ICD-9-CM codes for neurological impairment from previous studies (Adam Goldin, personal communication, 2008) and the tabular index of ICD-9-CM coding. ${ }^{9} 181922$ Neurological impairment included diagnoses such as cerebral palsy, hydrocephalus, leukodystrophy, and epilepsy.

Complex chronic conditions -We defined complex chronic conditions as respiratory, renal, gastrointestinal, metabolic, haematological, congenital or 
Table 1|Comparison of patients' characteristics between children with and without previous reflux related hospital admissions. Values are numbers (percentages)

\begin{tabular}{|c|c|c|c|c|}
\hline \multirow[b]{2}{*}{ Characteristic } & \multirow[b]{2}{*}{ Total $(n=3721)$} & \multicolumn{3}{|c|}{ History of reflux related admission } \\
\hline & & Yes $(n=2532)$ & No $(n=1189)$ & $P$ value \\
\hline \multicolumn{5}{|l|}{ Age: } \\
\hline 3 months & $337(9.2)$ & $147(5.8)$ & $190(16.0)$ & \multirow{6}{*}{$<0.001$} \\
\hline 3 to $<6$ months & $538(14.5)$ & $321(12.7)$ & $217(18.3)$ & \\
\hline 6 months to $<1$ year & $894(24.0)$ & $627(24.8)$ & $267(22.5)$ & \\
\hline 1 to $<1.5$ years & $583(15.7)$ & $426(16.8)$ & 157 (13.2) & \\
\hline 1.5 to $<3$ years & $883(23.7)$ & $648(25.6)$ & $235(19.8)$ & \\
\hline$\geq 3$ years & $486(13.1)$ & $363(14.3)$ & $123(10.3)$ & \\
\hline Male sex & $2125(57.1)$ & $1469(58.0)$ & $656(55.2)$ & 0.1020 \\
\hline \multicolumn{5}{|l|}{ Ethnicity: } \\
\hline Non-Hispanic white & 1918 (53.9) & $1342(55.3)$ & $576(50.8)$ & \multirow{5}{*}{0.0696} \\
\hline Black & $658(18.5)$ & $424(17.5)$ & $234(20.6)$ & \\
\hline Hispanic & $619(17.4)$ & $423(17.4)$ & $196(17.3)$ & \\
\hline Asian & $76(2.1)$ & $50(2.1)$ & $26(2.3)$ & \\
\hline Other & $291(8.2)$ & $189(7.8)$ & $102(9.0)$ & \\
\hline \multicolumn{5}{|l|}{ Insurance: } \\
\hline Government & $2118(56.9)$ & $1437(56.8)$ & $681(57.3)$ & \multirow{3}{*}{0.2336} \\
\hline Private & $950(25.5)$ & $634(25.0)$ & $316(26.6)$ & \\
\hline Other & $652(17.5)$ & $461(18.2)$ & $191(16.1)$ & \\
\hline \multicolumn{5}{|l|}{ Discharge disposition: } \\
\hline Home & $3246(87.4)$ & $2220(87.9)$ & $1026(86.4)$ & \multirow{3}{*}{0.2711} \\
\hline Died & $41(1.1)$ & $24(1.0)$ & $17(1.4)$ & \\
\hline Other & $428(11.5)$ & $283(11.2)$ & $145(12.2)$ & \\
\hline \multicolumn{5}{|l|}{ Median length of stay: } \\
\hline $1-5$ days & 1389 (37.3) & $980(38.7)$ & $409(34.4)$ & \multirow{4}{*}{$<0.001$} \\
\hline 6-10 days & $621(16.7)$ & $454(17.9)$ & $167(14.1)$ & \\
\hline 11-15 days & $382(10.3)$ & $272(10.7)$ & $110(9.3)$ & \\
\hline$\geq 16$ days & $1329(35.7)$ & $826(32.6)$ & $503(42.3)$ & \\
\hline \multicolumn{5}{|l|}{ Complex chronic conditions: } \\
\hline Cardiovascular & $1699(45.7)$ & $1187(46.9)$ & $512(43.1)$ & 0.0292 \\
\hline Respiratory & 1319 (35.5) & $989(39.1)$ & $330(27.8)$ & $<0.001$ \\
\hline Renal & $308(8.9)$ & $206(8.1)$ & $102(8.6)$ & 0.6476 \\
\hline Gastrointestinal & $260(7.0)$ & $187(7.4)$ & $73(6.1)$ & 0.1645 \\
\hline $\begin{array}{l}\text { Haematological or } \\
\text { immunological }\end{array}$ & $145(3.9)$ & $102(4.0)$ & $43(3.6)$ & 0.5449 \\
\hline Metabolic & $290(7.8)$ & $209(8.3)$ & $81(6.8)$ & 0.1260 \\
\hline Congenital or genetic & $1483(39.9)$ & $1068(42.2)$ & $415(34.9)$ & $<0.001$ \\
\hline Malignancy & $167(4.5)$ & $109(4.3)$ & $58(4.9)$ & 0.4310 \\
\hline \multicolumn{5}{|l|}{ Gastrostomy tube: } \\
\hline Previously & $240(6.5)$ & $192(7.6)$ & $48(4.0)$ & \multirow{4}{*}{$<0.001$} \\
\hline $\begin{array}{l}\text { During fundoplication } \\
\text { procedure }\end{array}$ & 2368 (63.6) & $1451(57.3)$ & 917 (77.1) & \\
\hline Both & $873(23.5)$ & $718(28.4)$ & $155(13.0)$ & \\
\hline Never & $240(6.5)$ & $171(6.8)$ & $69(5.8)$ & \\
\hline Ever had a tracheostomy & $631(17.0)$ & $448(17.7)$ & $183(15.4)$ & 0.0809 \\
\hline Presence of upper airway & $1243(33.4)$ & $912(36.0)$ & $331(27.8)$ & $<0.001$ \\
\hline
\end{tabular}

genetic defect, malignancy, and cardiovascular diagnoses expected to last longer than 12 months that involve either several different organ systems or one organ system severely enough to need specialty paediatric care and admission to hospital. ${ }^{2324}$ Complex chronic conditions are ICD-9-CM based and intended for use with paediatric administrative hospital admission data. We did not use the neuromuscular category, as the study cohort was assembled with neurological impairment as a criterion for inclusion.

Tracheostomy and upper airway anomalies - Other characteristics that may affect reflux related hospital admissions are tracheostomy and upper airway anomalies. We defined tracheostomy as ICD-9-CM procedure codes $31.1,31.2,317.4,317.5,96.55$, and 97.23 or diagnoses codes 519.00, 519.01, 519.02, 519.09, $\mathrm{v} 44.0$, and v55.0. ${ }^{2526}$ We defined upper airway anomalies as ICD-9-CM diagnoses codes 744.4x, 744.8x, 744.9, 747.21, 748.0, 748.2-4, 749.0x, 749.2x, 759.7, and $759.89 .{ }^{27} \mathrm{We}$ analysed tracheostomy and upper airway anomalies as present or absent for the patient during the study period.

Gastrostomy tube-Gastrostomy feeding tubes are common in this population. ${ }^{28}$ We defined gastrostomy tubes by using ICD-9-CM procedure codes 43.0, 43.19, 43.11, 43.1, and 97.02 or ICD-9-CM diagnoses codes $\mathrm{v} 44.1$, v55.1, and 536.4x. We analysed them as placed before the fundoplication, during the fundoplication procedure, both, or neither. We were unable to accurately identify gastrojejunal feeding tubes (another anti-reflux procedure) in the Pediatric Health Information System database.

\section{Hospitals' characteristics}

Hospitals' characteristics analysed were regional location (north east, south, central, west), average annual hospital volume of fundoplication during the study period, and percentage of fundoplication for children admitted with neurological impairment and gastrooesophageal reflux disease within each study hospital. We categorised the average annual hospital volume into quarters. We measured the percentage of fundoplication for the study population within hospitals to account for variability of indication for the procedure and institutional practices.

\section{Outcomes}

We defined reflux related hospital admission as admission for oesophagitis $(530.1,530.10,530.12,530.19)$ or gastro-oesophageal reflux disease (530.11, 530.81), aspiration pneumonia (507.0), pneumonia (480-486), asthma (493), or mechanical ventilation $(96.7,96.70$, $96.71,96.72) .{ }^{1829}$ We chose the outcomes of admission for oesophagitis, gastro-oesophageal reflux disease, and aspiration pneumonia as a complication of failure to treat gastro-oesophageal reflux disease. We chose the outcomes of admission for pneumonia, asthma, and mechanical ventilation for three reasons: they comprise a group of major respiratory problems that children with severe neurological impairment often encounter $^{3031}$; distinguishing aspiration pneumonia from another lower respiratory infection or event is difficult, unless it is clinically obvious (such as a witnessed aspiration event); and a reduction in mechanical ventilation rates, whatever the cause, is a more objective measure of the impact of fundoplication on this study cohort. 


\section{Statistical analyses}

We compared rates of reflux related hospital admission before and after fundoplication for the entire cohort. We truncated all outcomes to one year's follow-up. For the main analyses, we excluded patients who died after their fundoplication, in order to provide complete one year follow-up data. We excluded the admission for the fundoplication in both the before and after fundoplication admission rate data.

Rates of reflux related hospital admissions per child year before and after fundoplication were calculated directly. We calculated the "before" period as elapsed days of life during the study period from birth until the admission for the first fundoplication. The "after" period was one year post-fundoplication. ${ }^{18} \mathrm{We}$ used Poisson regression modelling for all analyses. We found no evidence of overdispersion of data. We calculated unadjusted incident rate ratios by dividing the postfundoplication reflux related admission rate by the pre-fundoplication rate. An incident rate ratio greater than 1 occurs when the post-fundoplication rate is greater than the pre-fundoplication rate (for example, with a harmful effect of fundoplication), a ratio of 1 indicates no differences in rates, and a ratio of less than 1 occurs when the post-fundoplication rate is lower than the pre-fundoplication rate (for example, with a protective effect of fundoplication). We calculated bivariate adjusted incident rate ratios while accounting for patients' characteristics and hospital level covariates individually.

Multivariate Poisson modelling included the significant bivariate variables and accounted for hospital clustering by using hierarchical models. As patient's age was the most influential covariate in the adjusted model, we treated age as a stratification factor and derived individual Poisson regression models for each age group. We also did the following subanalyses: cohort restriction to children with a "before" period of at least one year and cohort expansion to children who died in the one year after the fundoplication.

Table 2 |Comparison of hospitals' characteristics between children with and without previous reflux related hospital admission

\begin{tabular}{|c|c|c|c|c|}
\hline \multicolumn{5}{|l|}{ Census region: } \\
\hline North east & $352(9.5)$ & $256(10.1)$ & $96(8.1)$ & \multirow{4}{*}{0.0112} \\
\hline South & $1624(43.6)$ & $1063(42.0)$ & $561(47.2)$ & \\
\hline North central & $996(26.8)$ & $701(27.7)$ & $295(24.8)$ & \\
\hline West & $749(20.1)$ & $512(20.2)$ & 237 (19.9) & \\
\hline \multicolumn{5}{|c|}{ Annual No of fundoplications: } \\
\hline$\ll 40$ & $805(21.6)$ & $584(23.1)$ & $221(18.6)$ & \multirow{3}{*}{$<0.001$} \\
\hline $40-80$ & $898(24.1)$ & $631(24.9)$ & $267(22.5)$ & \\
\hline 180 & $2020(54.3)$ & $1317(52.0)$ & $701(59.0)$ & \\
\hline
\end{tabular}

Fundoplication for patients

with neurological impairment

and GERD (\%)

\begin{tabular}{|c|c|c|c|c|}
\hline$<10$ & 1049 (28.2) & $790(31.2)$ & 259 (21.8) & \multirow{3}{*}{$<0.001$} \\
\hline $10-20$ & $1790(48.1)$ & 1197 (47.3) & 593 (49.9) & \\
\hline$>20$ & $882(23.7)$ & $545(21.5)$ & 337 (28.3) & \\
\hline
\end{tabular}

GERD=gastro-oesophageal reflux disease.

\section{RESULTS}

Of the 955285 children eligible during the study period, $144749(15 \%)$ had neurological impairment. Of these, $27720(19 \%)$ developed gastro-oesophageal reflux disease and $6716(24 \%)$ had a fundoplication. Of these, 3721 (55\%) had at least one previous hospital admission and were included in the study cohort (fig 1). At the time of their first fundoplication, 1769 (48\%) were aged younger than 12 months, 1596 (42.9\%) were female, $1918 / 3562(53.9 \%)$ were white nonHispanic, 658 (18.5\%) were black, 619 (17.4\%) were Hispanic, and 2118 (56.9\%) used government insurance (table 1). After fundoplication, 3246/3715 $(87.4 \%)$ were discharged home and $41(1.1 \%)$ died.

The most common reasons for neurological impairment were seizures $(1777,47.8 \%)$, brain or spinal cord abnormalities $(1225,32.9 \%)$, genetic conditions (1063, $28.6 \%)$, and cerebral palsy $(990,26.6 \%)$. At least one other comorbid chronic condition was present in 2863 (76.9\%) children. A gastrostomy tube was placed during the fundoplication procedure in $2368(63.6 \%)$ patients; $631(17.0 \%)$ patients had a tracheostomy, and $1243(33.4 \%)$ had an upper airway anomaly (table 1). The percentage of fundoplication done on the study cohort within study hospitals ranged from $2.2 \%$ to $26.0 \%$ (table 2).

For the entire cohort, the unadjusted pre-fundoplication rate (per child year) for any reflux related hospital admission was 1.63 (95\% confidence interval 1.45 to 1.81). The post-fundoplication rate for any reflux related admission was 1.63 (1.43 to 1.81 ). The incident rate ratio was 0.98 ( 0.95 to $1.02 ; \mathrm{P}=0.3443)$. The unadjusted rates for aspiration pneumonia were $0.12(0.10$ to 0.14 ) pre-fundoplication and 0.1 (0.08 to 0.13$)$ postfundoplication; the incident rate ratio was 0.86 ( 0.76 to $0.97 ; \mathrm{P}=0.138$ ) (fig 2).

For the entire cohort, the adjusted pre-fundoplication and post-fundoplication rates (per child year) decreased for any reflux related hospital admission (incident rate ratio $0.69,0.67$ to $0.72 ; \mathrm{P}<0.01$ ), aspiration pneumonia $(0.71,0.62$ to $0.81 ; \mathrm{P}<0.01)$, gastrooesophageal reflux disease $(0.60,0.57$ to 0.63 ; $\mathrm{P}<0.01)$, and mechanical ventilation $(0.40,0.37$ to $0.43 ; \mathrm{P}<0.01)$. Hospital admissions increased for asthma (incident rate ratio $1.52,1.38$ to $1.67 ; \mathrm{P}<0.01$ ) and remained constant for pneumonia $(1.07,0.98$ to 1.17; $\mathrm{P}=0.16$ ) (fig 2).

When we specifically examined age by category in the Poisson regression models, hospital admissions for any reflux related cause decreased in all age groups, except those older than 36 months in whom admissions remained constant (table 3 ). We did not analyse admissions for oesophagitis within age groups owing to sparse observations. For patients under 12 months old the adjusted incident rate ratio was significantly less than 1 for aspiration pneumonia, gastro-oesophageal reflux disease, and mechanical ventilation but was either constant or greater than 1 (the post-fundoplication rate was higher than the pre-fundoplication rate) for asthma and pneumonia. The age effect was less consistent over the age of 12 months, depending on the 


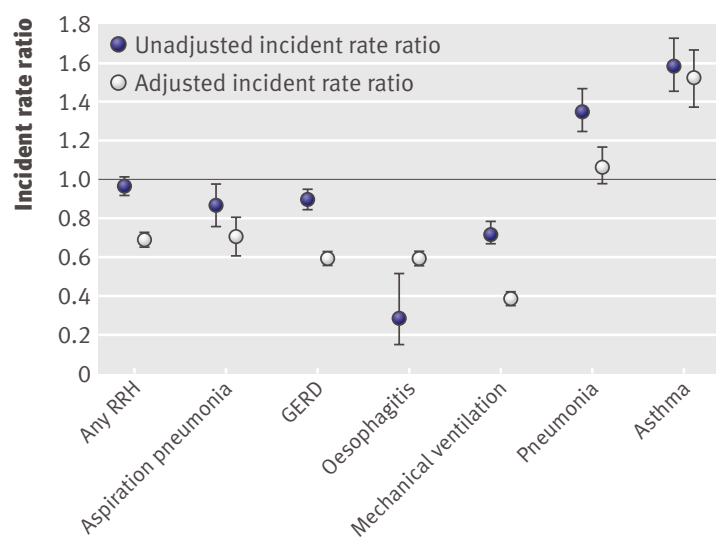

Fig 2 | Unadjusted and adjusted incident rate ratios (postfundoplication rate divided by pre-fundoplication rate), with 95\% Cls, for reflux related hospital admissions (RRH). $\mathrm{GERD}=$ gastro-oesophageal reflux disease

particular reflux related hospital admission being examined.

Subanalyses restricting the cohort to children with a "before" period of at least one year and expanding the cohort to children who died in the one year after the fundoplication gave similar findings to those for the entire cohort.

\section{DISCUSSION}

We observed a short term reduction in reflux related hospital admissions in this large multicentre cohort study of children with neurological impairment and gastro-oesophageal reflux disease who had a first fundoplication. A reduction in hospital admissions for aspiration pneumonia, gastro-oesophageal reflux disease, and mechanical ventilation occurred. However, admissions for pneumonia and asthma either remained constant or increased after fundoplication. The reduction in reflux related admissions was dependent on the age at which children with neurological impairment had their fundoplication.

\section{Comparison with other studies}

These findings are similar in two ways to those of Goldin et al, who evaluated reflux related hospital admissions before and after all fundoplications in the state of Washington between 1987 and 2001. ${ }^{18}$ Despite differences in age of the study cohorts, reflux related admissions for all combined conditions were lower after fundoplication in younger children (age $<1$ year ) with developmental delay. The magnitude of this effect across age categories - incident rate ratio 0.5 (0.4 to 0.63 ) for those under 12 months, 0.54 (0.41 to 0.71 ) for those between 12 and 48 months, and 1.38 (1.03 to 1.85 ) for those older than 48 months-was similar to our findings.

Our findings also differ from those of Goldin et al, who reported no difference in rates of hospital admission for aspiration pneumonia before and after fundoplication among children with developmental delay in any age group. Our findings differ from those of this seminal study for several possible reasons. Children with neurological impairment may experience different consequences of gastro-oesophageal reflux disease, such as aspiration pneumonia, as they grow older. The underlying reason for neurological impairment may make fundoplication a less desirable procedure to control aspiration pneumonia over the life of the child. The study by Goldin et al had more children with neurological impairment who were older and followed for their lifetime, whereas our study, by design, focused on a young cohort followed for one year, in order to capture their first fundoplication. Goldin et al examined data from a single state, whereas our study included data from 35 US states. This multi-state analysis may reflect differences beyond regional care, such as different selection of patients, which may have influenced the results.

Other studies have largely focused on other less objective outcomes such as control of symptoms and reporting of complications after fundoplication. ${ }^{610-13}$ Fonkulsrud et al reported in the largest case series to date (more than 7400 fundoplications) that outcomes reported by physicians from seven children's hospitals over a 20 year period describe resolution of symptoms in $85 \%$ of children with neurological impairment. ${ }^{8}$ Other smaller surgical case series describe less reduction in symptoms after fundoplication in children with neurological impairment. ${ }^{111415}$

Lasser et al published nationally weighted US data showing that fundoplications for children with neurological impairment decreased between 1996 and 2003 and that these children had fundoplication at 5 years of age or less. ${ }^{9}$ Although this study was unable to follow the children over time, the results are similar to ours, reflecting a young age for first fundoplication in children with neurological impairment. One other study examined hospital admissions before and after fundoplication in a small sample and, as in Goldin et al's study, found a reduction in admissions for children with neurological impairment. ${ }^{1832}$

\section{Strengths and limitations of study}

The strengths of this study include extending previously published methods from Goldin et al to a larger sample from several US states, thus increasing the generalisability of the results. Our outcome was more objective than those of several other studies examining the effectiveness of fundoplication in this population of patients. We studied children who had at least one visit to the study hospital before their first fundoplication, thus reducing potential selection bias.

Our study has several limitations inherent in the analysis of existing databases. The diagnoses of gastrooesophageal reflux disease (for our inclusion criteria) and reflux related hospital admission (our outcomes) were based on ICD-9-CM codes. We recognise that coding differences exist among hospitals, ${ }^{33}{ }^{34}$ but we have no reason to suspect systematic bias before and after the fundoplication that could have affected our admission rates. The Pediatric Health Information System does not contain clinical data to ascertain 
important information related to the fundoplication and reflux related admission. Clinical data are essential to substantiate the diagnosis of gastro-oesophageal reflux disease and the diagnoses that comprise reflux related hospital admissions, but we could not look at this in our administrative database study. For example, we could not determine if aspiration pneumonia after fundoplication was related to primary aspiration (for example, of secretions) or secondary aspiration (such as refluxed gastric contents). We could not examine how the diagnosis of gastro-oesophageal reflux disease was made for these children (clinical, radiographic, endoscopic), as the database does not contain outpatient or community data. Indications for fundoplication were unavailable. We could not accurately identify patients who had a different anti-reflux procedure, such as gastrojejunal feeding tubes, which could have influenced the results. ${ }^{16} 1920$

The reduction in hospital admissions may have represented physicians' bias in not labelling gastrooesophageal reflux disease or aspiration pneumonia for the post-fundoplication respiratory related admissions. Physicians may have been more likely to believe that the patient had asthma or pneumonia. This potential systematic bias cannot be determined in our study, but we believe that the reduction in admissions for mechanical ventilation make this possibility more remote. Our study may have overestimated the effect of fundoplication on reflux related hospital admissions for very young children, as their pre-fundoplication rates may be lower than those of children who were followed for a longer period of time before their fundoplication. The subanalysis of patients followed for at least one year pre-fundoplication was similar to the results for the entire cohort. Early intervention in children aged under 1 year may be, in part, natural recovery as opposed to the effects of treatments. By including age in the overall model, we attempted to adjust for secular trends, but residual confounding may still exist. We may have underestimated the morbidity associated with this procedure, as our definition of reflux related hospital admission did not include admissions for operative complications. We restricted our analyses to patients born during the study period to capture all procedures done in the respective children's hospitals. This may have restricted the generalisability of our results to fundoplication in older children with neurological impairment and gastrooesophageal reflux disease. Clinically, we found that most of these procedures were first done in younger children (unless the neurological impairment was acquired-for example, traumatic brain injury in older children), which was similar to observations by Lasser et al. ${ }^{9}$ However, we have limited data on the effectiveness of fundoplication in a large neonatal population, as our study design required a hospital admission to a study hospital before the fundoplication.

Patients may have been admitted to a non-Pediatric Health Information System hospital and thus missed in the outcome of another hospital admission in our study. However, in our experience, children with neurological impairment and gastro-oesophageal reflux disease having fundoplication receive the vast majority of their inpatient care at their local children's hospital. This study does not cover the effectiveness of fundoplication in the 2731 patients who were excluded because they did not have a previous admission. Many patients with neurological impairment and medically refractory gastro-oesophageal reflux disease are referred to children's hospitals for evaluation for a fundoplication.

Table 3 |Age specific models for reflux related hospital admissions, with unadjusted and adjusted incident rate ratios

\begin{tabular}{lcc}
\hline & \multicolumn{2}{c}{ Incidence rate ratio $(95 \% \mathrm{Cl})$} \\
\cline { 2 - 3 } $\begin{array}{l}\text { Age at fundoplication } \\
\text { Aspiration pneumonia }\end{array}$ & Unadjusted & Adjusted \\
\hline 0 to $<3$ months & $0.17(0.08$ to 0.33$)$ & $0.16(0.08$ to 0.33$)$ \\
\hline 3 to $<6$ months & $0.37(0.25$ to 0.55$)$ & $0.41(0.27$ to 0.61$)$ \\
\hline 6 to 112 months & $0.60(0.47$ to 0.78$)$ & $0.61(0.46$ to 0.79$)$ \\
\hline 12 months to $<18$ months & $0.86(0.66$ to 1.13$)$ & $0.87(0.66$ to 1.15$)$ \\
\hline 18 months to 33 years & $0.74(0.58$ to 0.94$)$ & $0.75(0.59$ to 0.96$)$ \\
\hline$\geq 3$ years & $1.31(0.94$ to 1.82$)$ & $1.35(0.97$ to 1.88$)$
\end{tabular}

Gastro-oesophageal reflux disease

\begin{tabular}{|c|c|c|}
\hline 0 to $<3$ months & 0.27 (0.22 to 0.34$)$ & $0.27(0.21$ to 0.33$)$ \\
\hline 3 to $<6$ months & 0.39 (0.35 to 0.45$)$ & $0.40(0.35$ to 0.46$)$ \\
\hline 6 to $<12$ months & 0.57 (0.51 to 0.62$)$ & $0.55(0.50$ to 0.61$)$ \\
\hline 12 months to $<18$ months & 0.70 (0.62 to 0.79$)$ & $0.70(0.62$ to 0.79$)$ \\
\hline 18 months to $<3$ years & 0.74 (0.66 to 0.82$)$ & $0.75(0.67$ to 0.83$)$ \\
\hline$\geq 3$ years & 1.12 (0.94 to 1.32$)$ & $1.10(0.93$ to 1.31$)$ \\
\hline \multicolumn{3}{|l|}{ Mechanical ventilation } \\
\hline 0 to $<3$ months & 0.17 (0.13 to 0.22$)$ & $0.17(0.13$ to 0.23$)$ \\
\hline 3 to $<6$ months & 0.25 (0.21 to 0.29$)$ & $0.25(0.21$ to 0.30$)$ \\
\hline 6 to $<12$ months & $0.41(0.36$ to 0.47$)$ & $0.41(0.36$ to 0.47$)$ \\
\hline 12 months to $<18$ months & $0.56(0.46$ to 0.67$)$ & $0.56(0.46$ to 0.68$)$ \\
\hline 18 months to $<3$ years & $0.54(0.44$ to 0.65$)$ & $0.54(0.44$ to 0.65$)$ \\
\hline$\geq 3$ years & 1.21 (0.91 to 1.60$)$ & $1.18(0.89$ to 1.57$)$ \\
\hline \multicolumn{3}{|l|}{ Pneumonia (non-aspiration) } \\
\hline 0 to $<3$ months & $1.63(0.82$ to 3.26$)$ & 1.77 (0.85 to 3.67) \\
\hline 3 to $<6$ months & $0.95(0.71$ to 1.26$)$ & $0.95(0.71$ to 1.27$)$ \\
\hline 6 to $<12$ months & 1.03 (0.88 to 1.22$)$ & $1.04(0.87$ to 1.23$)$ \\
\hline 12 months to $<18$ months & 0.82 (0.67 to 1.00$)$ & $0.82(0.67$ to 1.00$)$ \\
\hline 18 months to $<3$ years & $1.02(0.86$ to 1.21$)$ & $1.02(0.85$ to 1.21$)$ \\
\hline$\geq 3$ years & 2.11 (1.71 to 2.6$)$ & $2.14(1.73$ to 2.64$)$ \\
\hline \multicolumn{3}{|l|}{ Asthma } \\
\hline 0 to $<3$ months & 1.98 (0.71 to 5.52$)$ & $1.79(0.64$ to 5.05$)$ \\
\hline 3 to $<6$ months & $1.56(0.99$ to 2.45$)$ & $1.70(1.05$ to 2.76$)$ \\
\hline 6 to $<12$ months & 2.59 (2.04 to 3.29$)$ & $2.84(2.19$ to 3.67$)$ \\
\hline 12 months to $<18$ months & 1.57 (1.28 to 1.91$)$ & $1.49(1.22$ to 1.83$)$ \\
\hline 18 months to $<3$ years & $1.24(1.07$ to 1.44$)$ & $1.25(1.08$ to 1.46$)$ \\
\hline$\geq 3$ years & 1.70 (1.37 to 2.12$)$ & $1.63(1.30$ to 2.03$)$ \\
\hline \multicolumn{3}{|c|}{ Any reflux related hospital admission } \\
\hline 0 to $<3$ months & $0.30(0.26$ to 0.35$)$ & $0.29(0.25$ to 0.34$)$ \\
\hline 3 to $<6$ months & $0.40(0.37$ to 0.44$)$ & $0.41(0.38$ to 0.45$)$ \\
\hline 6 to $<12$ months & $0.66(0.62$ to 0.70$)$ & $0.66(0.62$ to 0.70$)$ \\
\hline 12 months to $<18$ months & 0.79 (0.73 to 0.85$)$ & $0.78(0.72$ to 0.85$)$ \\
\hline 18 months to $<3$ years & $0.81(0.76$ to 0.87$)$ & $0.82(0.77$ to 0.88$)$ \\
\hline$\geq 3$ years & $1.40(1.27$ to 1.55$)$ & $1.39(1.26$ to 1.54$)$ \\
\hline
\end{tabular}




\section{WHAT IS ALREADY KNOWN ON THIS TOPIC}

Studies of the effectiveness of fundoplication in children with neurological impairment report conflicting results

Studies have either focused on potentially biased outcomes, such as physicians' reports of resolution of symptoms, or had methodological weaknesses

One study reported a reduction in reflux related hospital admissions among children with neurological impairment in a single US state

\section{WHAT THIS STUDY ADDS}

Fundoplication was associated with a reduction in reflux related hospital admissions

Comparative effectiveness data for other treatments (such as gastrojejunal feeding tubes) are unknown

Lack of data of previous admissions outside of the Pediatric Health Information System database limited our ability to assess whether this cohort's outcomes were better, no different, or worse than those of the included children.

We could not make adjustments for functional limitations owing to lack of information in the database. We did not measure other important outcomes, such as health related quality of life of either the caregiver or the child over time,${ }^{22}$ nor any complications or the cost of the fundoplication or resultant inpatient care, as these were beyond the scope of our study.

\section{Conclusions and policy implications}

We observed a short term reduction in reflux related hospital admission in this large multicentre cohort study of children with neurological impairment and gastro-oesophageal reflux disease who had fundoplication. Reduced admission is certainly beneficial to children, their family, and the hospitals that serve them. However, these admissions are one component in a series of outcomes that providers may discuss with families of children with neurological impairment. Demonstrable reduction in symptoms, improvement in the child's and caregivers' health related quality of life, and reduction in complications should also be considered. Multicentre prospective comparative trials (for example, for anti-reflux procedures such as gastrojejunal feeding tubes versus fundoplication) should be considered with these outcomes, in order to determine the true efficacy of anti-reflux procedures in reducing the complications of gastro-oesophageal reflux disease in children with neurological impairment. Longer term outcomes need to be studied, as the risks and benefits for an intervention may change over time. These studies may help to define subsets of patients who may have more or less benefit from an anti-reflux operation or who may be more or less disposed to have complications. Conflicting results may emerge, making fundoplication an intervention that requires the families' and clinicians' complete understanding and partnership before embarking along a particular treatment pathway.

In conclusion, children with neurological impairment and gastro-oesophageal reflux disease who have fundoplication experienced reduced hospital admissions for aspiration pneumonia, gastro-oesophageal reflux disease, and mechanical ventilation. However, admissions for pneumonia remained constant and those for asthma increased after fundoplication. Comparative effectiveness data for other treatments (such as gastrojejunal feeding tubes) are unknown.

Contributors: All authors were responsible for study conception and design. MH acquired the data. RS, JGB, MH, and DCB analysed and interpreted the data and drafted the manuscript. All authors critically revised the manuscript. $\mathrm{MH}$ did the statistical analysis and provided technical support. JGB, MH, ED, MO'G, JMD, and DCB provided supervision. $\mathrm{MH}$ and $\mathrm{RS}$ are the guarantors.

Funding: RS and JGB are the recipients of the Eunice Kennedy Shriver National Institute of Child Health and Human Development, National Institutes of Health (NIH) career development awards K23 HD052553 and K23 HD058092. This project was supported in part by the Children's Health Research Center at the University of Utah and Primary Children's Medical Center Foundation. None of the study funders had any role in the study design; in the collection, analysis, and interpretation of data; in the writing of the report; or in the decision to submit the article for publication. The researchers had complete independence from the study funders.

Competing interests: None declared

Ethical approval: This study was approved by the institutional review boards of Children's Hospital, Boston, and the University of Utah Health Sciences Center and Primary Children's Medical Center, Salt Lake City. Data sharing: No additional data available.

1 Chaney RH, Eyman RK, Miller CR. Comparison of respiratory mortality in the profoundly mentally retarded and in the less retarded. J Ment Defic Res 1979;23:1-7.

2 Plioplys AV, Kasnicka I, Lewis S, Moller D. Survival rates among children with severe neurologic disabilities. South Med J 1998;91:161-72.

3 Maudsley G, Hutton JL, Pharoah PO. Cause of death in cerebral palsy: a descriptive study. Arch Dis Child 1999;81:390-4.

4 Marik PE. Aspiration pneumonitis and aspiration pneumonia. N Engl J Med 2001;344:665-71.

5 Sondheimer JM, Morris BA. Gastroesophageal reflux among severely retarded children. J Pediatr 1979;94:710-4.

6 Spitz L, Roth K, Kiely EM, Brereton RJ, Drake DP, Milla PJ. Operation for gastro-oesophageal reflux associated with severe mental retardation. Arch Dis Child 1993;68:347-51.

7 Sullivan PB, Lambert B, Rose M, Ford-Adams M, Johnson A, Griffiths P. Prevalence and severity of feeding and nutritional problems in children with neurological impairment: Oxford feeding study. Dev Med Child Neurol 2000;42:674-80.

8 Fonkalsrud EW, Ashcraft KW, Coran AG, Ellis DG, Grosfeld JL, Tunell WP, et al. Surgical treatment of gastroesophageal reflux in children: a combined hospital study of 7467 patients. Pediatrics 1998;101:419-22.

9 Lasser MS, Liao JG, Burd RS. National trends in the use of antireflux procedures for children. Pediatrics 2006;118:1828-35.

10 Bourne MC, Wheeldon C, MacKinlay GA, Munro FD. Laparoscopic Nissen fundoplication in children: 2-5-year follow-up. Pediatr Surg Int 2003;19:537-9.

11 Dedinsky GK, Vane DW, Black T, Turner MK, West KW, Grosfeld JL. Complications and reoperation after Nissen fundoplication in childhood. Am / Surg 1987;153:177-83.

12 Gilger MA, Yeh C, Chiang J, Dietrich C, Brandt ML, El-Serag HB. Outcomes of surgical fundoplication in children. Clin Gastroenterol Hepatol 2004;2:978-84.

13 Powers CJ, Levitt MA, Tantoco J, Rossman J, Sarpel U, Brisseau G, et al. The respiratory advantage of laparoscopic Nissen fundoplication. I Pediatr Surg 2003;38:886-91.

14 Martinez DA, Ginn-Pease ME, Caniano DA. Recognition of recurrent gastroesophageal reflux following antireflux surgery in the neurologically disabled child: high index of suspicion and definitive evaluation. J Pediatr Surg 1992;27:983-8, discussion 988-90.

15 Martinez DA, Ginn-Pease ME, Caniano DA. Sequelae of antireflux surgery in profoundly disabled children. J Pediatr Surg 1992;27:267-71, discussion 271-3.

16 Albanese CT, Towbin RB, Ulman I, Lewis J, Smith SD. Percutaneous gastrojejunostomy versus Nissen fundoplication for enteral feeding of the neurologically impaired child with gastroesophageal reflux. J Pediatr 1993;123:371-5 
17 Burd RS, Price MR, Whalen TV. The role of protective antireflux procedures in neurologically impaired children: a decision analysis. J Pediatr Surg 2002;37:500-6.

18 Goldin AB, Sawin R, Seidel KD, Flum DR. Do antireflux operations decrease the rate of reflux-related hospitalizations in children? Pediatrics 2006;118:2326-33.

19 Srivastava R, Downey EC, O'Gorman M, Feola P, Samore M, Holubkov R, et al. Impact of fundoplication versus gastrojejunal feeding tubes on mortality and in preventing aspiration pneumonia in young children with neurologic impairment who have gastroesophageal reflux disease. Pediatrics 2009;123:338-45.

20 Wales PW, Diamond IR, Dutta S, Muraca S, Chait P, Connolly B, et al. Fundoplication and gastrostomy versus image-guided gastrojejunal tube for enteral feeding in neurologically impaired children with gastroesophageal reflux. J Pediatr Surg 2002;37:407-12.

21 Veenker E. Enteral feeding in neurologically impaired children with gastroesophageal reflux: Nissen fundoplication and gastrostomy tube placement versus percutaneous gastrojejunostomy. J Pediatr Nurs 2008;23:400-4

22 Srivastava R, Downey EC, Feola P, Samore M, Coburn L, Holubkov R, et al. Quality of life of children with neurological impairment who receive a fundoplication for gastroesophageal reflux disease. J Hosp Med 2007;2:165-73.

23 Feudtner C, Christakis DA, Connell FA. Pediatric deaths attributable to complex chronic conditions: a population-based study of Washington State, 1980-1997. Pediatrics 2000;106:205-9.

24 Feudtner C, Hays RM, Haynes G, Geyer JR, Neff JM, Koepsell TD. Deaths attributed to pediatric complex chronic conditions: national trends and implications for supportive care services. Pediatrics 2001;107:E99.
25 Berry JG, Lieu TA, Forbes PW, Goldmann DA. Hospital volumes for common pediatric specialty operations. Arch Pediatr Adolesc Med 2007;161:38-43.

26 Lewis CW, Carron JD, Perkins JA, Sie KC, Feudtner C. Tracheotomy in pediatric patients: a national perspective. Arch Otolaryngol Head Neck Surg 2003;129:523-9.

27 Kremer B, Botos-Kremer Al, Eckel HE, Schlondorff G. Indications, complications, and surgical techniques for pediatric tracheostomies —an update. J Pediatr Surg 2002;37:1556-62.

28 Partrick DA. Gastrointestinal tract feeding access and the role of fundoplication in combination with gastrostomy. Curr Opin Pediatr 2007;19:333-7.

29 DeFrances CJ, Hall MJ. 2005 national hospital discharge survey. Adv Data 2007;385:1-19.

30 Graham RJ, Fleegler EW, Robinson WM. Chronic ventilator need in the community: a 2005 pediatric census of Massachusetts. Pediatrics 2007;119:e1280-7.

31 Murphy N, Such-Neibar T. Cerebral palsy diagnosis and management: the state of the art. Curr Probl Pediatr Adolesc Health Care 2003;33:146-69.

32 Rice H, Seashore JH, Touloukian RJ. Evaluation of Nissen fundoplication in neurologically impaired children. J Pediatr Surg 1991;26:697-701.

33 Berthelsen CL. Evaluation of coding data quality of the HCUP National Inpatient Sample. Top Health Inf Manage 2000;21:10-23.

34 Lorence DP, Ibrahim IA. Benchmarking variation in coding accuracy across the United States. J Health Care Finance 2003;29:29-42.

Accepted: 31 July 2009 